\title{
Overview of liver disorders during pregnancy at a tertiary care centre: Uttarakhand scenario
}

\section{Monika Ramola*, Shweta Jain, Vineeta Gupta, Neeta Bansal, Parul Singh}

Department of Obstetrics and Gynecology, SGRRIMHS, Dehradun, Uttarakhand, India

Received: 28 June 2017

Accepted: 25 July 2017

\section{*Correspondence:}

Dr. Monika Ramola,

E-mail: dr.monika.ms@gmail.com

Copyright: (c) the author(s), publisher and licensee Medip Academy. This is an open-access article distributed under the terms of the Creative Commons Attribution Non-Commercial License, which permits unrestricted non-commercial use, distribution, and reproduction in any medium, provided the original work is properly cited.

\begin{abstract}
Background: Liver disorders in pregnancy encompass a spectrum of diseases encountered during antenatal and postnatal period resulting in abnormal liver function tests and hepatobiliary dysfunction or both. This study is aimed at determining the causes of liver disorders during pregnancy and associated maternal and fetal outcomes over a period of 3 years at a tertiary care centre of Dehradun.

Methods: All case records of patients with liver disorders during pregnancy from May 2013 to May 2016 were retrieved from medical record department of SGRRIMHS, Dehradun and analyzed for various causes of liver disorders and associated maternal and fetal outcomes.

Results: During the three-year study period, 146 pregnant patients were found to have liver disorders. The study found that viral hepatitis was the most common cause of liver disorders followed by Intrahepatic cholestasis of pregnancy IHCP. There were 6 mortalities among the study group out of which hepatitis E was the culprit for maternal mortality in two patients. The serum bilirubin levels were directly proportional to the maternal deaths.

Conclusions: Liver disorders during pregnancy are rare but an important cause of maternal and fetal morbidity and mortality. Early recognition, timely referral and aggressive management may lead to better maternal and fetal outcome.
\end{abstract}

Keywords: Acute fatty liver of pregnancy (AFLP), DIC (Disseminated intravascular coagulation), HELLP (Hemolysis, elevated liver enzymes and low platelet count), ICU (Intensive care unit), Intrahepatic cholestasis of pregnancy (IHCP), Liver disorders

\section{INTRODUCTION}

Liver disorders in pregnancy encompass a spectrum of diseases encountered during antenatal and postnatal period resulting in abnormal liver function tests and hepatobiliary dysfunction or both. Incidence of liver disorders has been reported to be 3-5\% worldwide ${ }^{1}$

The diagnosis of liver disease in pregnancy is challenging and relies on laboratory investigations. Signs and symptoms are often not specific and consist of jaundice, nausea, vomiting and abdominal pain. The underlying disorders can have a significant effect on morbidity and mortality in both mother and fetus, hence a diagnostic workup should be promptly initiated.

Liver disorders in pregnancy include diseases induced by the pregnancy such as acute fatty liver of pregnancy (AFLP) and intrahepatic cholestasis of pregnancy (IHCP), diseases that existed before pregnancy that could potentially flare up during pregnancy such as autoimmune hepatitis and Wilson's disease, diseases not 
related to the pregnancy but that could affect the pregnant woman at any time during gestation such as viral hepatitis.

Though appears to be affecting a small percentage, the impact on maternal and fetal health takes a major toll on antenatal patients and health care system. Hence, we undertook this study at a tertiary care institute of Dehradun which is a tertiary level referral centre and caters to the remotest areas of the hilly terrains of Uttarakhand.

\section{METHODS}

The study was conducted at SGRRIMHS, Dehradun, India from May 2013 to May 2016. All pregnant women with liver disorders based on clinical and biochemical evidences were included in the study.

They were subjected to a detailed clinical history, physical and obstetric examination. Apart from routine antenatal investigations, specific tests like liver function tests, viral markers, total bile acids, renal function tests, coagulation profile and abdominal ultrasound scan etc were done to identify the etiology of liver disorders.

Various causes of liver disorders, maternal and fetal outcomes were noted and data was analyzed. The patients were jointly managed by team of gynecologist, gastroenterologist and intensivist.

\section{RESULTS}

During the study period of 3 years there were 6575 deliveries at our tertiary care centre. Out of them, 146 patients were found to have liver disorders.

Table 1: the incidence.

\begin{tabular}{|c|c|c|}
\hline Causes & Number & $\%$ \\
\hline Viral hepatitis & 75 & 51.3 \\
\hline Hepatitis B & 43 & 29.4 \\
\hline Hepatitis A & 10 & 6.8 \\
\hline Hepatitis C & 12 & 8.2 \\
\hline Hepatitis E & 10 & 6.8 \\
\hline IHCP & 45 & 30.8 \\
\hline Preeclampsia, Eclampsia, HELLP & 10 & 6.8 \\
\hline AFLP & 4 & 2.7 \\
\hline Obstructive jaundice & 3 & 2 \\
\hline Dengue & 2 & 1.3 \\
\hline Typhoid & 2 & 1.3 \\
\hline Cholecystitis & 2 & 1.3 \\
\hline Scrub typhus & 1 & 0.7 \\
\hline Cirrhosis with portal hypertension & 1 & 0.7 \\
\hline
\end{tabular}

The calculated incidence of liver disorders was $2.2 \%$. The commonest cause for liver disorders was viral hepatitis followed by IHCP and preeclampsia. Hepatitis B was responsible for the maximum number of hepatitis cases Rest of the indications are shown in Table 1.

Table 2: Parity distribution.

\begin{tabular}{|lll|}
\hline Parity & Number & $\%$ \\
\hline G1 & 75 & 51.4 \\
\hline G3 & 34 & 23.3 \\
\hline G4 & 24 & 16.4 \\
\hline G5 & 7 & 4.8 \\
\hline G6 & 3 & 2.05 \\
\hline
\end{tabular}

$75(51.3 \%)$ patients were primigravida and seventy one $(48.6 \%)$ patients were multigravida (Table 2 ).

Table 3: Age distribution.

\begin{tabular}{|lll|}
\hline Age (years) & Number & $\%$ \\
\hline$<20$ & 6 & 4.1 \\
\hline $21-25$ & 63 & 43.1 \\
\hline $26-30$ & 58 & 39.8 \\
\hline $31-35$ & 15 & 10.3 \\
\hline$>35$ & 4 & 2.7 \\
\hline
\end{tabular}

The most common age group was 21-25 years $(43.1 \%)$ followed by $26-30$ years $(39.8 \%$ ) (Table 3$)$.

Table 4: Mode of delivery.

\begin{tabular}{|lll|}
\hline Mode of deliver & Number & $\%$ \\
\hline Vaginal delivery & 95 & 65.1 \\
\hline LSCS & 51 & 34.9 \\
\hline
\end{tabular}

$95(65.1 \%)$ patients had normal vaginal delivery whereas $58(34.9 \%)$ patients had undergone LSCS (Table 4).

Table 5: Serum bilirubin levels.

\begin{tabular}{|lll|}
\hline Serum Bilirubin & Number & $\%$ \\
\hline $1.2 \mathrm{mg} / \mathrm{dl}$ & 89 & 60.9 \\
\hline $1.2-3$ & 27 & 18.5 \\
\hline$>3-6$ & 8 & 5.5 \\
\hline$>6-10$ & 10 & 6.8 \\
\hline$>10-15$ & 7 & 4.8 \\
\hline$>15$ & 5 & 3.4 \\
\hline
\end{tabular}

The serum bilirubin level was less than $1.2 / \mathrm{dl}$ in 89 patients (Table 5).

Table 6: Birth weight.

\begin{tabular}{|lll|}
\hline Birth weight $(\mathrm{kg})$ & Number & $\%$ \\
\hline$<1.5 \mathrm{~kg}$ & 9 & 6.2 \\
\hline $1.5-2 \mathrm{~kg}$ & 22 & 15.1 \\
\hline $2-2.5 \mathrm{~kg}$ & 41 & 28.1 \\
\hline $2.5-3 \mathrm{~kg}$ & 52 & 35.6 \\
\hline$>3 \mathrm{~kg}$ & 22 & 15 \\
\hline
\end{tabular}


$98(67.1 \%)$ patients had term deliveries whereas 48 $(32.9 \%)$ patients had preterm deliveries. There were 15 $(10.3 \%)$ stillbirths and $72(49.3 \%)$ babies had birth weight less than $2.5 \mathrm{~kg}$. NICU stay was required in 13 $(8.9 \%)$ babies. Neonatal outcome is shown in Table 6.

Table 7: Morbidity.

\begin{tabular}{|c|c|c|}
\hline Morbidity & Number & $\%$ \\
\hline Hepatic encephalopathy & 3 & 2 \\
\hline DIC & 5 & 3.4 \\
\hline Sepsis & 2 & 1.4 \\
\hline ICU Stay & 18 & 12.3 \\
\hline Ventilatory support & 12 & 8.2 \\
\hline Renal failure requiring dialysis & 2 & 1.4 \\
\hline PPH & 11 & 7.4 \\
\hline
\end{tabular}

Complications leading to morbidity like PPH, hepatic encephalopathy, DIC, coagulation failure, sepsis, renal failure, ICU stay and ventilatory support was noted in 42 patients (Table 7).

Table 8: Causes of mortality.

\begin{tabular}{|lll|}
\hline Causes of mortality & Number & $\%$ \\
\hline HEV & 2 & 1.4 \\
\hline DIC & 2 & 1.4 \\
\hline AFLP & 1 & 0.6 \\
\hline Hepatorenal failure with DIC & 1 & 0.6 \\
\hline
\end{tabular}

There were 6 mortalities, causes leading to deaths are shown in Table 8 . All fatalities had serum bilirubin more than $6 \mathrm{mg} \%$.

\section{DISCUSSION}

Incidence of liver disorders has been reported to be $0.4-$ 0.9 per thousand deliveries in various studies. ${ }^{2}$ During the study period of three years, there were 6575 deliveries at our institute. Out of them liver disorders were noted in 146 patients making an incidence of $2.2 \%$ per thousand deliveries. Nagaria $\mathrm{T}$ has reported $0.55 \%$ per thousand deliveries whereas Jayati $\mathrm{N}$ has reported the incidence to be $0.95 \%$ in their respective studies. ${ }^{2,3}$ Present incidence is comparatively higher than other studies probably because our centre is largest in the hilly states of Uttarakhand catering to a large area of hilly terrain.

Viral hepatitis was the most common cause leading to $51.3 \%$ of liver disorders in our study. Hepatitis B was causing the maximum number of hepatitis cases which was up to $58 \%$ of all infective viral hepatitis followed by hepatitis C, A and E. Hepatitis E though was causing $13.5 \%$ of all infections was among the leading cause behind maternal morbidity and mortality. Pregnancy appears to be a potential risk factor for viral replication because of low immune status of Indian /Asian women. In non-pregnant women the case fatality rate is less than $0.1 \%$ whereas in pregnant women case fatality rate is
$25 \%$. Hepatitis B and C run a benign course. Nagaria T also reported viral hepatitis to be the commonest cause. ${ }^{2}$ Krishnamoorthy $\mathbf{J}$ and Shukla et al have reported the incidence of viral hepatitis to be $51 \%$ and $57 \%$ respectively. ${ }^{4,5}$

Incidence of IHCP was noted to be $30.82 \%$ becoming the second major cause of liver disorders where total bile acids and liver enzymes were elevated; present incidence is similar to study by Satia MN et al.

Other common causes were preeclampsia and related complications like eclampsia and HELLP syndrome accounting to 10 cases $(6.8 \%)$ followed by AFLP which was seen in 4 cases $(2.7 \%)$.

There were $48(32.8 \%)$ preterm vaginal deliveries. Still births were $15(10.3 \%)$ and neonatal deaths were $6(4 \%)$ leading to perinatal mortality rate of $14.4 \%$. $49 \%$ of babies were of low birth weight i.e. less than $2.5 \mathrm{kgs}$. Konareddy and Singh have reported perinatal mortality to be $25 \%$ and $45.45 \%$ in their studies. ${ }^{6,8}$ In present study, hepatitis B and IHCP were the predominant causes of liver disorders which do not lead to perinatal mortality. Hence, our perinatal mortality rate is slightly lower than as observed in above mentioned studies.

Severe maternal morbidity was notably higher in patients with serum bilirubin more than $6 \mathrm{mg} / \mathrm{dl}$. Complications encountered in our patients were atonic PPH (7.4\%), encephalopathy $(2 \%)$, DIC $(3.4 \%)$, renal failure $(1.4 \%)$ and sepsis $(1.4 \%)$. ICU stay was required in $12.3 \%$ cases and ventilatory support was required in $8.2 \%$ of cases.

Various studies have reported jaundice to be the major indirect cause for maternal mortality in India. The incidence has been reported to be 5\%-30\%. Maternal deaths were directly proportional to the level of serum bilirubin which was observed in several studies. ${ }^{9}$ Maternal mortality rate was $4.1 \%(6 / 146)$ in present study. Nagaria $\mathrm{T}$ has reported $14.4 \%$ mortality rate whereas Singh has noted $10 \%$ mortality rate in their studies. ${ }^{2,8}$ The causes of mortality were DIC in 2 patients, hepatorenal failure with DIC in 1 patient, AFLP in 1 patient and $\mathrm{HEV}$ in 2 patients. Hepatitis $\mathrm{E}$ was responsible for $33.3 \%$ mortality. Hepatitis $\mathrm{E}$ has a case fatality of less than $0.1 \%$ in nonpregnant females whereas in pregnant women it has a mortality of $15-45 \% .{ }^{10}$ AFLP is an uncommon but potentially fatal cause of liver disorders. It is a diagnosis of exclusion and liver biopsy is not mandatory to make a diagnosis. AFLP contributed to mortality rate of $16.6 \%$ and a case fatality rate of $25 \%$ in present study. Maternal and perinatal mortality due to AFLP has come down from 75 and $85 \%$ to 18 and $23 \%$ respectively due to prompt diagnosis and management. ${ }^{11,12}$

Out of the four cases of AFLP, we were able to save three cases by timely delivery and supportive treatment. 


\section{CONCLUSION}

Liver disorders during pregnancy are uncommon but potentially dangerous. Timely diagnosis and a good intensive management protocol can prevent mortality and save lives.

Funding: No funding sources Conflict of interest: None declared

Ethical approval: The study was approved by the Institutional Ethics Committee

\section{REFERENCES}

1. Jain RK. Management of jaundice in pregnancy. Medicine update. 2010;20:470-6.

2. Nagaria T, Agarwal S. Fetomaternal outcome in jaundice during pregnancy. J Obstet Gynecol India. 2005;55:424-7.

3. Jayati N, Bajpayi G, Sharma R. A clinical study on jaundice in pregnancy with special emphasis on fetomaternal outcome. IOSR-JDMS. 2015;3:116-9.

4. Krishnamoorthy J, Murugesan A. Jaundice during pregnancy-maternal and fetal outcome. Int J Reprod Contracept Obstet Gynaecol. 2016;5:2541-5.

5. Shukla S, Mehta G, Jais M, Singh A. A prospective study on viral hepatitis in pregnancy: seroprevalance and fetomaternal outcome of 100 cases. J Biosci Tech. 2011;2(3):279-86.
6. Konareddy T, Krithika K A. Jaundice in pregnancy, a clinical study at JSS hospital, Mysore, Karnataka, India. Int J Reprod Contracept Obstet Gynaecol.2016; 5:2257-60.

7. Satia MN, Jandhyala M. A study of fetomaternal outcomes in cases of jaundice at a tertiary care centre. Int J Reprod Contracept Obstet Gynaecol. 2016; 5:2352-7.

8. Singh S, Chauhan R, Patel RS. Jaundice in pregnancy. J Obstet Gynaecol. 1991;41:187-9.

9. Trivedi SS, Goyal U, Gupta U. A study of maternal mortality due to viral hepatitis. J Obstet Gynecol India. 2003;53:551-3.

10. Khuroo MS. Hepatitis E: the enterically transmitted non-A, non-B hepatitis. J Gastroenterol. 1991;10:96100 .

11. Hin Hin Ko. Acute fatty liver of pregnancy. Canadian J Gastroenterol. 2006;20(1):25-30.

12. Knox T, Olans L. Liver disorders in pregnancy. $\mathrm{N}$ Engl J Med. 1996;335:569-76.

Cite this article as: Ramola M, Jain S, Gupta V, Bansal N, Singh P. Overview of liver disorders during pregnancy at a tertiary care centre:

Uttarakhand scenario. Int J Reprod Contracept Obstet Gynecol 2017;6:3979-82. 